\title{
CD2 Negative
}

National Cancer Institute

\section{Source}

National Cancer Institute. CD2 Negative. NCI Thesaurus. Code C147090.

Indicates that expression of C2 has not been detected in a sample. 